\title{
Removal of nickel from wastewater using an agricultural adsorbent
}

\author{
Krishnie Moodley', Ruella Singh', Evans T Musapatika', Maurice S Onyango ${ }^{2}$ and Aoyi Ochieng ${ }^{3 *}$ \\ ${ }^{1}$ School of Chemical and Metallurgical Engineering, University of the Witwatersrand, Private Bag X3 Wits 2050, South Africa \\ ${ }^{2}$ Department of Chemical and Metallurgical Engineering, Tshwane University of Technology, Pretoria, Private Bag X680, \\ Pretoria, 0001, South Africa \\ ${ }^{3}$ Department of Chemical Engineering, Vaal University of Technology, Private Bag X021, Vanderbijlpark, 1900, South Africa
}

\begin{abstract}
Chemical wastewater streams may contain toxic compounds which are non-biodegradable, and therefore require advanced treatment techniques such as adsorption. However, application of adsorption processes is often limited by the cost of adsorbents. In this study, the adsorption capacity of a low-cost adsorbent (pine sawdust) was investigated by treating wastewater containing nickel (II) and other heavy metal ions. Results were analysed using response surface methodology and a factorial design was employed to determine the interactive effects of the various factors on the adsorption capacity. Furthermore, Langmuir and Freundlich adsorption isotherms were fitted to experimental data to characterise the adsorption of the nickel ions by the pine sawdust. As a result, the highest adsorption capacity was attained at the combined effect of low adsorbent dose, high $\mathrm{pH}$ and high initial concentration. On the other hand, the Freundlich isotherm fitted the experimental data better than the Langmuir isotherm. Results of this study indicate that the use of pine sawdust could be a promising solution to the elimination of nickel ions from multi-component aqueous solutions.
\end{abstract}

Keywords: sawdust, adsorption, nickel ions, wastewater, isotherm

\section{Nomenclature}

$\beta_{\mathrm{i}} \quad$ dimensionless regression coefficients

$C_{o} \quad$ Initial concentration $(\mathrm{mg} / \ell)$

$C_{e} \quad$ Equilibrium concentration $(\mathrm{mg} / \ell)$

$i^{e} \quad=0,1,2, \ldots \ldots, k$

$k \quad$ Number of variables

$K_{\mathrm{F}} \quad$ Freundlich constant related with adsorption capacity (mg/g)

$K_{\mathrm{L}} \quad$ Langmuir affinity constant $(\ell / \mathrm{mg})$

$m \quad$ Mass of dry adsorbent $(\mathrm{g})$

$n$ dimensionless Freundlich constant related with adsorption intensity

$q_{e} \quad$ Equilibrium adsorption capacity $(\mathrm{mg} / \mathrm{g})$

$q_{\max } \quad$ Maximum monolayer adsorption capacity (mg/g)

$q_{\mathrm{Ni}} \quad$ Predicted adsorption capacity for Nickel (mg/g)

$R^{2} \quad$ dimensionless correlation coefficient

$V \quad$ Volume of wastewater $(\ell)$

$x_{1} \quad$ dimensionless coded variable for dose

$x_{2} \quad$ dimensionless coded variable for $\mathrm{pH}$

$x_{3}$ dimensionless coded variable for initial concentration

$Y \quad$ Predicted response

\section{Introduction}

A vast number of raw materials for industrial processes originate from agricultural activities, which result in the production of chemical and solid wastes. The chemical wastes arise from the use of pesticides, dyes and fertilisers while the solid wastes include bagasse, sawdust, rice husk, peanut shell and

\footnotetext{
* To whom all correspondence should be addressed.

표 +2716 509884; fax: +2716 9509796 ;

e-mail: ochienga@vut.ac.za

Received 26 November 2009; accepted in revised form 8 November 2010.
}

coffee husk, among others. Interestingly, the agricultural solid wastes can be converted to adsorption media and used to treat the chemical wastes; a concept of using waste to treat waste. By this concept, the cost of adsorption material for wastewater treatment, which is a major constraint in wastewater management, is generally reduced. Due to environmental concerns and the demand for high-quality water, there has been an increase in regulations controlling the discharge of heavy metals and non-biodegradable toxic compounds into water bodies. This has resulted in developing toxic waste removal techniques such that only minute quantities remain in the wastewater discharged into water bodies. Secondary wastewater treatment is not completely adequate in removing toxic material and thus advanced methods have become necessary. Secondary methods are employed in conjunction with advanced methods to separate the recalcitrant organic compounds and non-biodegradable inorganic compounds (Singh et al., 2007). Advanced methods of removing toxic compounds from wastewater include membrane separation (Mavrov et al., 2006), ion exchange (Cavaco et al., 2007), lime precipitation (Zhang et al., 2007), neutralisation, metal hydroxide precipitation (Ayyappan et al., 2003), electrolytic methods (Kurt et al., 2007) and adsorption (Dean et al., 1972). However, these processes are costly (Dae and Young, 2005); in particular, the use of activated carbon and ion exchange resins is not suitable for developing countries due to their high capital and operational costs (Raji and Anirudhan, 1997).

Adsorption has gained a relatively wide application due to the fact that there are several types of adsorbents that are commonly used, which includes clay, activated carbon, zeolite and silica gel and the agricultural adsorbents such as coffee husk (Kumar, 2006), peanut shells (Wafwoyo et al., 1999), bagasse (Azhar et al., 2005), rice husk (Kumar and Bandyopadhyay, 2006) and sawdust (Argun et al., 2007). Thus, by using natural, abundant, cheap agricultural wastes (Taty-Costodes et al., 
2003), the adsorption of pollutants from aqueous solutions can be much more economical with regard to other similar physicochemical processes (Mahvi, 2008). The concept of using waste has not been investigated in detail. To the best of our knowledge, no work has been reported on the use of pine sawdust in the removal of nickel (II) ions from multi-component aqueous solutions using the response surface methodological approach; many researchers use the one-factor-at-a-time (OFAT) method. However, this method is extremely time consuming and expensive since it requires a large number of experiments (Elibol, 2002). The aim of this study was to investigate the interactive effects of operating parameters such as adsorbent dose, $\mathrm{pH}$ and initial concentration on adsorption capacity of pine sawdust towards nickel (II) ions using the response surface methodology (RSM). Furthermore, the adsorption capacity of pine sawdust in the removal of nickel (II) ions from multi-component aqueous solutions was determined.

\section{Materials and methods}

\section{Adsorbent preparation and wastewater synthesis}

Pine sawdust collected from a local company was ground and sieved to a particle size range of 500-850 $\mu \mathrm{m}$. It was then placed in stainless steel trays and dried in an oven (EcoTherm) at $50^{\circ} \mathrm{C}$ for $24 \mathrm{~h}$. A mass of $100 \mathrm{~g}$ was placed in a $1 \ell$ glass beaker and $660 \mathrm{~m} \ell$ of $0.6 \mathrm{M}$ citric acid solution was added. The mixture was manually stirred for $30 \mathrm{~min}$, and then separated by vacuum filtration. The wet sawdust was then spread in stainless steel trays and dried in an oven at $50^{\circ} \mathrm{C}$ for $24 \mathrm{~h}$ and then the temperature was raised to $120^{\circ} \mathrm{C}$ and maintained for $90 \mathrm{~min}$. The sawdust was allowed to cool and washed 5 times using hot distilled water $\left(60-80^{\circ} \mathrm{C}\right)$ and then dried at $50^{\circ} \mathrm{C}$ for $24 \mathrm{~h}$ (Wafwoyo et al., 1999). Finally, the temperature was raised to $250^{\circ} \mathrm{C}$ and maintained for $24 \mathrm{~h}$, after which the sawdust particles were removed from the stainless steel trays and stored for adsorption tests. No leaching experiments were carried out to check for the presence of toxic soluble leachate, which could possibly emanate from pine sawdust especially when its source has been previously treated with pesticides. Fourier Transform Infrared (FT-IR) spectra of the pine sawdust before and after adsorption were recorded in the range 500 to 4000 $\mathrm{cm}^{-1}$ on an FT-IR (Bruker, Tensor $27 \mathrm{TPR}$ ) system, to explore the number and positions of the functional groups responsible for adsorption.

The stock solutions (1 $000 \mathrm{mg} / \ell)$ of $\mathrm{Ni}(\mathrm{II}), \mathrm{Co}(\mathrm{II})$ and $\mathrm{Fe}(\mathrm{III})$ prepared from the metal nitrates were diluted with distilled water to obtain the desired initial concentrations according to the levels specified in Table 1. The zero level concentration of heavy metals was 10 times that reported by Patel and Mudamwar (2002) for a particular petrochemical wastewater sample. Thus, the medium values in the reported ranges were multiplied by 10 and taken as the zero levels in the present study. Additionally, the composition and concentrations of the synthetic aqueous solutions prepared fall within the range of the typical petrochemical wastewater described in the Pollution Prevention and Abatement Handbook (World Bank Group, 2008), which specifies a heavy metal concentration range of 0.1 to $100 \mathrm{mg} / \ell$. The $\mathrm{pH}$ of the solutions was adjusted using either dilute $\mathrm{HNO}_{3}$ or $\mathrm{NaOH}$. A high $(+) \mathrm{pH}$ level of 3.9, which is below the $\mathrm{pH}$ point of precipitation $\left(\mathrm{pH}_{\mathrm{pp}}\right)$ for each of the metal hydroxides, was chosen to prevent possible precipitation (Al-Degs et al., 2006). All the $\mathrm{pH}$ measurements were done using a pH meter (LabX Direct-SevenMulti, Mettler Toledo) and all the chemicals used were of analytical grade, supplied by Merck Chemical Company (South Africa).

\section{Experimental design and optimisation of parameters}

The adsorbent dose, $\mathrm{pH}$ and initial concentration were chosen as independent variables and the adsorption capacity, $q_{e}$ as the dependent output response variable. A $2^{3}$ full-factorial design with 4 centre points leading to 12 experimental runs was performed (Table 2). The centre point replicates were chosen to verify any change in the estimation procedure, as a measure of precision property (Ravikumar et al., 2007). For statistical calculations, the variables $X_{\mathrm{i}}$ were coded as $x_{i,}$ according to the following relationship:

$$
x_{i}=\frac{X_{i}-X_{0}}{\Delta X}
$$

where:

$x_{\mathrm{i}}$ is the independent variable coded value;

$X_{i}$, independent variable real value;

$X_{\mathrm{o}}$, independent variable real value on the centre point; and

$\Delta X$, step change value (Elibol, 2002) of which the values for dose, $\mathrm{pH}$ and initial concentration $\left(C_{\mathrm{o}}\right)$ in this case are 2.0, 1.3 and 0.88 , respectively.

Table 1 gives the range and the levels of the variables (low and high) investigated in this study.

\begin{tabular}{|l|c|c|c|c|}
\hline \multicolumn{5}{|c|}{ Table 1 } \\
The experimental range and levels of the \\
independent variables \\
\hline Factor & $\begin{array}{c}\text { Coded } \\
\text { symbol }\end{array}$ & \multicolumn{3}{c|}{ Levels } \\
\cline { 2 - 5 } & $x_{1}$ & $-\mathbf{1}$ & $\mathbf{0}$ & $\mathbf{1}$ \\
\hline Dose $(\mathrm{g})$ & $x_{2}$ & 1.3 & 4.0 & 6.0 \\
\hline $\mathrm{pH}$ & $x_{3}$ & 0.875 & 1.75 & 2.625 \\
\hline$[\mathrm{Ni}(\mathrm{II}) \text { and } \mathrm{Co}(\mathrm{II})]_{0}(\mathrm{mg} / \ell)$ & $x_{3}$ & 2.125 & 4.25 & 6.375 \\
\hline$[\mathrm{Fe}(\mathrm{III})]_{0}(\mathrm{mg} / \ell)$ & & &
\end{tabular}

The quadratic model for predicting the adsorption capacity for nickel was expressed according to Eq. (2):

$$
\begin{aligned}
Y= & \beta_{o}+\beta_{1} x_{1}+\beta_{2} x_{2}+\beta_{3} x_{3}+\beta_{11} x_{1}^{2}+\beta_{22} x_{2}{ }^{2}+\beta_{33} x_{3}{ }^{2} \\
& +\beta_{12} x_{1} x_{2}+\beta_{13} x_{1} x_{3}+\beta_{23} x_{2} x_{3}
\end{aligned}
$$

where:

$Y$ is the response predicted by the model, whilst $x_{1}, x_{2}, x_{3}$ are the coded forms of dose, $\mathrm{pH}$ and initial concentration, respectively. The term $\beta_{o}$ is the offset term, $\beta_{1}, \beta_{2}$ and $\beta_{3}$ are linear terms, $\beta_{11}, \beta_{22}$ and $\beta_{33}$ are the quadratic terms whilst $\beta_{12}, \beta_{13}$ and $\beta_{23}$ are the interaction terms (Bhatia et al., 2009).

The analysis of variance (ANOVA) for the quadratic model was carried out to establish its statistical significance at $5 \%$ level of significance (95\% confidence level). Design Expert Version 6.0.6 (Stat Ease, Inc., Minneapolis, USA) and Matlab Version 7.0.1 software were used for regression and graphical analysis of the data obtained. The statistical significance of the regression coefficients was determined by the Student's $t$-test and $p$-values.

\section{Adsorption procedure}

All adsorption experiments conducted were of the batch type. A $100 \mathrm{~m} \ell$ wastewater solution was contacted with the desired 
mass of pine sawdust in $250 \mathrm{~m} \ell$ Erlenmeyer flasks. Blank solutions (solution without the adsorbent) were also included. The flasks were covered with parafilm. The mixture was shaken at $250 \mathrm{r} / \mathrm{min}$ in an incubator with shaking platform (FSIM-SPO16, Labcon) at $25^{\circ} \mathrm{C}$ for a predetermined contact time of $45 \mathrm{~h}$. The supernatant was separated by filtration. Initial and final heavy metal ion concentrations were determined using the Atomic Absorption Spectrometer (SpectroAA 55 B, Varian). The response, i.e., adsorption capacity, $q_{\mathrm{e}}$, was calculated as:

$$
q_{e}=\frac{\left(C_{o}-C_{e}\right) V}{m}
$$

where:

$C_{\mathrm{o}}$ and $C_{\mathrm{e}}$ are the initial and equilibrium adsorbate concentrations in solution $(\mathrm{mg} / \ell)$, respectively

$V$ is a known volume of synthetic wastewater $(\ell)$

$m$ is a known mass of adsorbent $(\mathrm{g})$.

\section{Adsorption isotherms}

The adsorption isotherm data for nickel ions were generated by contacting a fixed amount of pine sawdust $(4 \mathrm{~g})$ with $100 \mathrm{~m} \ell$ of synthetic wastewater with the concentration of metal ions ranging from 2 to $20 \mathrm{mg} / \ell$ in $250 \mathrm{~m} \ell$ flasks. The flasks were shaken at $250 \mathrm{r} / \mathrm{min}$ in an incubator with shaking platform at $25^{\circ} \mathrm{C}$ for $45 \mathrm{~h}$. At the end, the residual concentrations of the nickel ions were measured and the adsorption capacity, $q_{\mathrm{e}}$, was determined. The results were fitted to the commonly-used Langmuir and Freundlich isotherms. Equation (4) is the linear form of the Langmuir isotherm:

$$
\frac{1}{q_{e}}=\left(\frac{1}{K_{L} q_{\max }}\right) \frac{1}{C e}+\frac{1}{q_{\max }}
$$

where:

$q_{\mathrm{e}}$ is the adsorption capacity at equilibrium ( $\mathrm{mg} / \mathrm{g}$ )

$q_{\max }$ is the theoretical maximum adsorption capacity of the adsorbent $(\mathrm{mg} / \mathrm{g})$

$K_{\mathrm{L}}$ is the Langmuir affinity constant $(\ell / \mathrm{mg})$

$C_{\mathrm{e}}$ is the supernatant equilibrium concentration of the system (mg/ $\ell$ ) (Febrianto et al., 2009).

The Freundlich isotherm model can also be expressed in the linearised logarithmic form (Eq. (5)):

$$
\log q_{e}=\log K_{F}+\left(\frac{1}{n}\right) \log C_{e}
$$

where:

$K_{\mathrm{F}}$ is the Freundlich constant related with adsorption capacity $(\mathrm{mg} / \mathrm{g})$

$n$ is the heterogeneity coefficient (dimensionless).

\section{Results and discussion}

\section{Surface functional groups}

Citric acid provides additional carboxyl groups to those on pine sawdust surfaces and substantially increases its metal uptake (Mcsweeny et al., 2006). The spectra shown in Fig. 1 display a number of absorption peaks, indicating the complex nature of the surfaces of pine sawdust. The peak at $3381.2 \mathrm{~cm}^{-1}$ before adsorption can be attributed to the hydrogen-bonded $\mathrm{OH}$ group of alcohols and phenols (Yang and Lua, 2003) and it shifted to $3217.2 \mathrm{~cm}^{-1}$ after adsorption. Also, the peak at $1184.3 \mathrm{~cm}^{-1}$

\begin{tabular}{|c|c|c|c|c|c|c|c|c|}
\hline & $2^{3}$ & ull-f & ctor & $\begin{array}{r}\mathrm{Ta} \\
\text { ial de }\end{array}$ & $\begin{array}{l}\text { ble } 2 \\
\text { sign }\end{array}$ & with $4 \mathrm{c}$ & entre poir & nts \\
\hline Standard & Cor & ed le & els & & tual le & vels & $q_{\mathrm{e}} \times 10^{-3}$ & ${ }^{3}(\mathrm{mg} / \mathrm{g})$ \\
\hline & $\mathrm{x}_{1}$ & $x_{2}$ & $x_{3}$ & $\begin{array}{c}\text { Dose } \\
\text { (g) }\end{array}$ & $\mathrm{pH}$ & $\begin{array}{c}\mathrm{C}_{\mathrm{o}} \\
(\mathrm{mg} / \mathrm{l})\end{array}$ & \begin{tabular}{|l|} 
Observed \\
\end{tabular} & Predicted \\
\hline 1 & -1 & -1 & -1 & 2.0 & 1.3 & 0.875 & 5.00 & 1.93 \\
\hline 2 & +1 & -1 & -1 & 6.0 & 1.3 & 0.875 & 1.79 & 4.87 \\
\hline 3 & -1 & +1 & -1 & 2.0 & 3.9 & 0.875 & 28.83 & 32.0 \\
\hline 4 & +1 & +1 & -1 & 6.0 & 3.9 & 0.875 & 6.29 & 3.22 \\
\hline 5 & -1 & -1 & +1 & 2.0 & 1.3 & 2.625 & 7.50 & 11.0 \\
\hline 6 & +1 & -1 & +1 & 6.0 & 1.3 & 2.625 & 3.21 & 0.13 \\
\hline 7 & -1 & +1 & +1 & 2.0 & 3.9 & 2.625 & 65.90 & 63.00 \\
\hline 8 & +1 & +1 & +1 & 6.0 & 3.9 & 2.625 & 17.68 & 21.00 \\
\hline 9 & 0 & 0 & 0 & 4.0 & 2.6 & 1.750 & 5.92 & 5.71 \\
\hline 10 & 0 & 0 & 0 & 4.0 & 2.6 & 1.750 & 5.83 & 5.71 \\
\hline 11 & 0 & 0 & 0 & 4.0 & 2.6 & 1.750 & 5.33 & 5.71 \\
\hline 12 & 0 & 0 & 0 & 4.0 & 2.6 & 1.750 & 5.75 & 5.71 \\
\hline
\end{tabular}
before sorption is associated with $\mathrm{C}-\mathrm{O}$ stretching vibrations in carboxylic acids (Pavia et al., 1987), and it shifted to

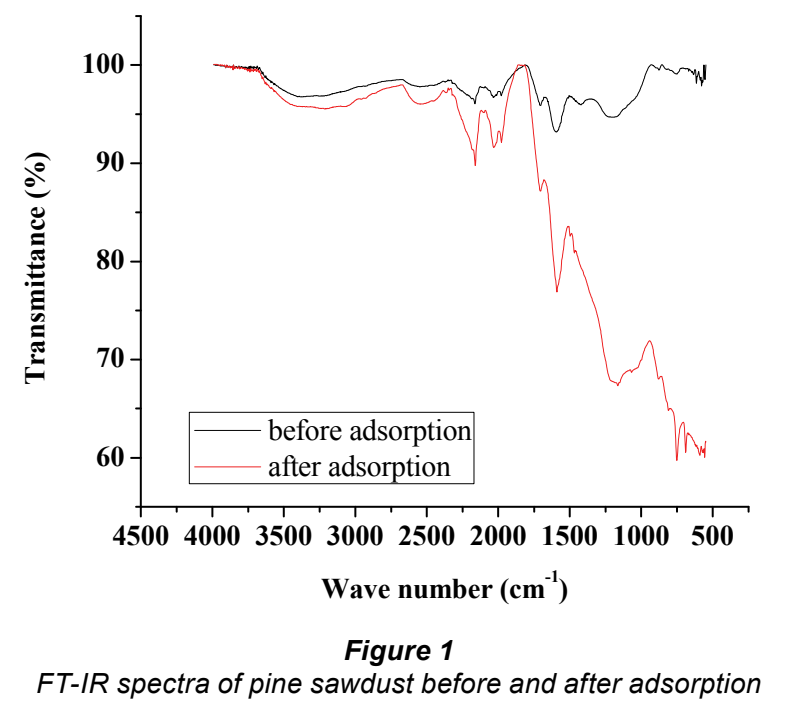

$1163.1 \mathrm{~cm}^{-1}$ after adsorption. These major shifts in band suggest that the alcohols/phenols and carboxylic acid groups were involved in metal binding. Agricultural biomasses mainly consist of lignin, cellulose, hemicelluloses and some proteins which make them effective adsorbents for heavy metal cations (Garg et al., 2008). In addition, the band at $1597.0 \mathrm{~cm}^{-1}$ represents the $\mathrm{C}=\mathrm{C}$ skeletal stretch in condensed aromatic system and a peak at $754.2 .3 \mathrm{~cm}^{-1}$ can be assigned to the out-of-plane $\mathrm{C}-\mathrm{H}$ bending modes of an aromatic compound (Al-Qodah and Shawabkah, 2009).

\section{Fitting of a quadratic model}

By applying multiple regression analysis methods, the predicted adsorption capacities can be obtained and given as:

$$
q_{N i}=0.123-0.0098 x_{1}+0.0127 x_{2}-0.0079 x_{1} x_{2}-0.112 x_{3}^{2}(6)
$$

where:

$q_{N i}$ is the predicted adsorption capacity for nickel ions

$x_{1}, x_{2}, x_{3}$ are the coded values of the test variables, dose $(\mathrm{g})$,

$\mathrm{pH}$ and initial concentration $(\mathrm{mg} / \ell)$, respectively.

The statistical significance of the second-order model equation was evaluated by the $F$-test and the analysis of variance 
(ANOVA), which is summarised in Table 4. In this work, the model acceptance was based on the $95 \%$ confidence level. In order for a term to be significant at this confidence level, the calculated probability should be lower than 0.05 (Bhatia et al., 2009). The ANOVA revealed that this regression model is statistically significant, as is evident from the Fisher's $F$-test with a very low probability value $(<0.0033)$ i.e the associated Prob. $>F$ value for the model is lower than 0.05 . The lack-of-fit measures the failure of the model to represent data in the experimental domain at points which are not included in the regression. The associated Prob.> $F$ for the lack-of-fit is 0.0515 which is greater than 0.05 and this indicates that the lack-of fit is not significant. Thus, the non-significant value of lack of fit $(>0.05)$ reveals that the quadratic model is statistically significant (Sharma et al., 2009). A standard deviation of $4.35 \times 10^{-3}$ and a relatively lower value of the coefficient of variation $(\mathrm{CV}=32.9 \%)$ indicates a better precision and reliability of the experiments carried out. The model presented a relatively high $R^{2}$ value (0.9792) explaining $97.9 \%$ of the variables; dose, $\mathrm{pH}$ and initial concentration in the response and it indicates that $2.1 \%$ of the total variation is not explained by the model.

\begin{tabular}{|l|c|c|c|c|c|}
\hline \multicolumn{7}{|c|}{ Table 3} \\
Analysis of variance (ANOVA) for the quadratic model
\end{tabular}

The model Eq. (6) has dimensionless input values, i.e, it consists of coded variables only. However, in practical cases a model equation with the real variables must be used. Thus, the relationship between each coded and real variable was deduced from Eq. (1) and substituted into the model Eq. (6); upon rearrangement, Eq. (7) was obtained:

$$
\begin{aligned}
q_{N i}= & 0.192+0.00105 \text { Dose }+0.0125 p H \\
& -0.00127 \text { Dose. } p H-0.0602 C_{o}^{2}
\end{aligned}
$$

Equation (7) was then used to plot the 3-dimensional surfaces of dose $-\mathrm{pH}$ at constant $C_{\mathrm{o}}$, (Fig. 2a), dose $-C_{\mathrm{o}}$ at constant $\mathrm{pH}$ (Fig. 2b) and $\mathrm{pH}-\mathrm{C}_{\mathrm{o}}$ at constant dose (figure not shown) as a function of adsorption capacity. No curvature is displayed in Fig. 2a since $C_{\mathrm{o}}$ was kept constant, and as a result there were no second-order terms in Eq. (7).

\section{Interactive effect of parameters}

Low doses resulted in high adsorption capacities $(q)$, whilst high doses resulted in low $q_{\mathrm{e}}$ values (Fig. 2a). At the same time, the adsorption capacity slightly increased with increase in solution $\mathrm{pH}$. Thus, the removal of nickel increases with increasing $\mathrm{pH}$ and decreasing dose. This trend predicted by the model is consistent with the experimental results shown in Table 2, in which the highest adsorption capacity of $65.9 \times 10^{-3} \mathrm{mg} / \mathrm{g}$ was observed at low dose and high $\mathrm{pH}$. It can be assumed from these results and (a)
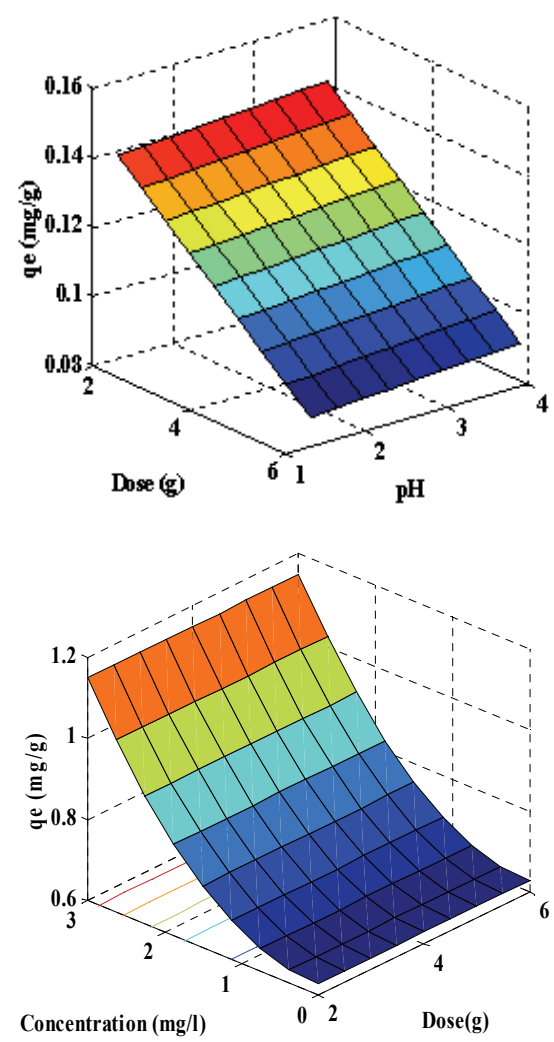

Figure 2

Adsorption capacity as a function of:

(a) dose and $\mathrm{pH}$ at constant initial concentration and (b) initial concentration and dose at constant $\mathrm{pH}$

the FT-IR spectra that the possible adsorption mechanism is probably due to ion exchange. High concentrations of $\mathrm{H}^{+}$ ions at low $\mathrm{pH}$ of 1.3 may change the direction of reversible ion exchange equilibrium back to starting materials to give low $q_{\mathrm{e}}$ values (Yu et al., 2001). At a high $\mathrm{pH}$ of 3.9, relatively low concentration of $\mathrm{H}^{+}$ions means less competition for the adsorption site on sawdust particles, which results in high $q_{\mathrm{e}}$ values for nickel ions. The FT-IR spectra showed that the $-\mathrm{OH}$ and $-\mathrm{COOH}$ groups took part in the sorption process. However the sites responsible for the sorption process might not be exclusively due to the $-\mathrm{OH}$ and $-\mathrm{COOH}$ groups; other sites on the adsorbent may also contribute to the sorption process and physical adsorption is quite probable (Yu et al., 2001).

The decrease in adsorption capacity with increase in dose (Fig. 2a) could be due to the aggregation or overlapping of adsorption sites caused by overcrowding of the sawdust particles). Such aggregation would lead to decrease in total surface area of the sorbent and an increase in diffusional path length (Shukla et al., 2002). This trend is comparable to that reported by Ayyappan et al. (2003) for the removal of $\mathrm{Pb}$ (II) from aqueous solution using a low-cost adsorbent. Figure $2 b$ shows that the sorption capacity of sawdust for nickel ions increased with increasing initial concentration. This trend can be explained by the fact that initial concentration provides a significant driving force of the concentration gradient to overcome all the mass transfer resistance between the solid and aqueous phase. This is in agreement with the findings of Ghorbani et al. (2008). The highest adsorption capacity obtained for nickel was $65.9 \times 10^{-3} \mathrm{mg} / \mathrm{g}$ at low dose, high initial concentration and high $\mathrm{pH}$. 

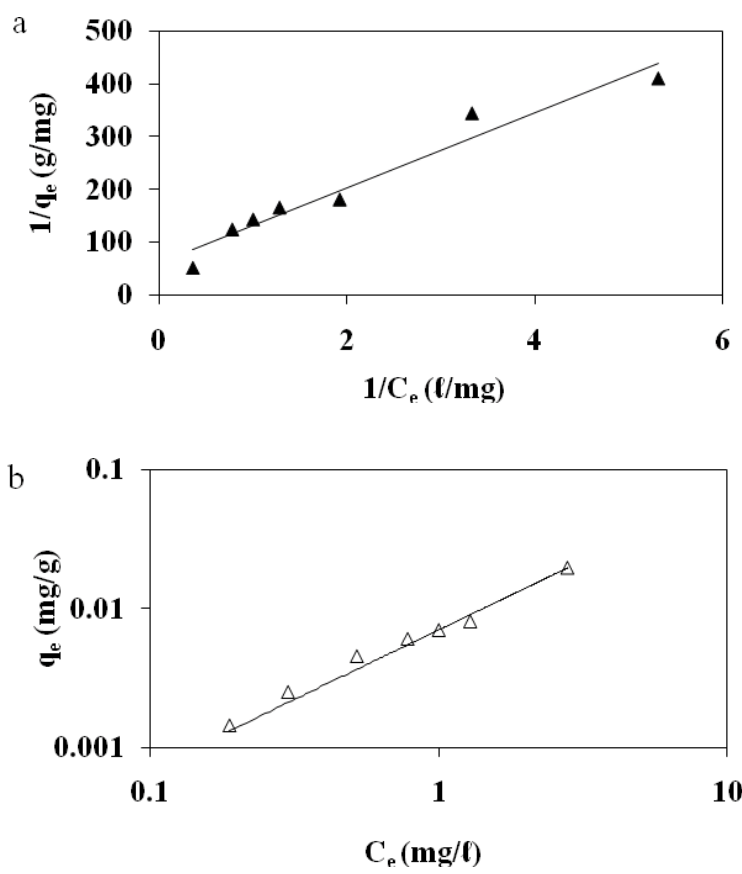

Figure 3

Plot of (a) Langmuir and (b) Freundlich adsorption isotherm $\left(\mathrm{pH}=2.6\right.$, dose $=4.0 \mathrm{~g}$, temperature $\left.=25^{\circ} \mathrm{C}\right)$.

\section{Adsorption isotherms}

The adsorption data was correlated with commonly-used adsorption isotherms, namely; Langmuir and Freundlich models. The Langmuir isotherm was obtained by plotting $1 / q_{e}$ versus $1 / C_{e}$ (Fig. 3a) whilst the Freundlich isotherm was obtained by plotting $q_{e}$ versus $C_{e}$ on a logarithmic scale (Fig. $3 \mathrm{~b}$ ) and the constants obtained along with the correlation coefficients; $R^{2}$ values are shown in Table 4.

\begin{tabular}{|l|c|c|c|c|c|c|}
\hline \multicolumn{7}{|c|}{ Table 4 } \\
\hline \multirow{3}{*}{ Metal ion } & \multicolumn{3}{|c|}{ Freundlich } & \multicolumn{3}{c|}{ Langmuir } \\
\cline { 2 - 7 } & $\mathbf{1 / n}$ & $\begin{array}{c}\boldsymbol{K}_{F} \\
(\mathrm{mg} / \mathrm{g})\end{array}$ & $\boldsymbol{R}^{2}$ & $\begin{array}{c}\boldsymbol{q}_{\max } \\
(\mathrm{mg} / \mathrm{g})\end{array}$ & $\begin{array}{c}\boldsymbol{K}_{L} \\
(\ell / \mathrm{mg})\end{array}$ & $\boldsymbol{R}^{2}$ \\
\hline Nickel (II) & 0.2105 & 0.005 & 0.9844 & 0.0100 & 0.8800 & 0.9110 \\
\hline
\end{tabular}

The Freundlich model presented a high correlation coefficient $\left(R^{2}=0.9844\right)$ as compared to that obtained for the Langmuir model (0.9110). Thus, it is evident that the equilibrium data conforms to the Freundlich model, which assumes heterogeneity in the surface binding process. This observation is consistent with the heterogeneous nature of pine sawdust which consists of different active sites such as $-\mathrm{OH}$ and $-\mathrm{COOH}$ groups as revealed by the FT-IR spectra (Fig. 1). The Langmuir model assumes homogeneity (i.e., all the active sites possess equal affinity) in the surface binding process and that is why it could not fit well to the experimental data. Agricultural adsorbents display heterogeneity (Gupta and Ali, 2004). This observation was also reported by Fritz and Schlünder (1981). The intensity of adsorption, $1 / n$, lies between 0 and 1 , which implies stronger interaction between the pine sawdust and the nickel (II) ions (Site, 2001). Disposal of pine sawdust after use can be accomplished by either composting or incineration
(Marshall and Johns, 1996) and the metal residues could be recovered by subsequent treatment of the post-combustion ash (Wase and Forster, 1997).

\section{Conclusions}

Pine sawdust has been successfully used to remove nickel (II) ions from multi-component aqueous solutions. Assessment of the interactive effects of process variables (dose, $\mathrm{pH}$ and initial concentration) revealed that the system was sensitive to the tested process variables and the process was technically feasible. A combination of low adsorbent dose ( $2 \mathrm{~g})$, high initial concentration $(2.625 \mathrm{mg} / \ell)$ and high $\mathrm{pH}(3.9)$ resulted in the highest adsorption capacity of $65.9 \times 10^{-3} \mathrm{mg} / \mathrm{g}$. Fitting the experimental data to a second-order response surface model resulted in the model slightly over-predicting the adsorption capacities. Moreover, the adsorption process was better described by the Freundlich isotherm than the Langmuir model. Thus, the Freundlich isotherm can be used as a predictive tool. Further studies need to be carried out to investigate the effects of metal ion interaction during adsorption. In this study pine sawdust, a natural, abundant and low-cost adsorbent has shown adsorption capabilities for nickel (II) ions; hence, it could be an option in the quest to use waste to treat wastewater.

\section{References}

AL-DEGS YS, EL-BARGHOUTHI MI, ISSA AA, KHRAISHEH MA and WALKER GM (2006) Sorption of $\mathrm{Zn}$ (II), Pb(II), and Co(II) using natural sorbents: Equilibrium and kinetic studies. Water Res. 40 2645-2658.

AL-QODAH Z and SHAWABKAH R (2009) Production and characterization of granular activated carbon from activated sludge. Braz. J. Chem. Eng. 26 127-136.

ARGUN ME, DURSUN S, OZDEMIR C and KARATAS M (2007) Heavy metal adsorption by modified oak sawdust: Thermodynamics and kinetics. J. Hazard. Mater. 141 77-85.

AYYAPPAN R, SOPHIA AC, SWAMINATHAN K and SANDHYA $\mathrm{S}$ (2003) Removal of $\mathrm{Pb}(\mathrm{II})$ from aqueous solution using carbon derived from agricultural wastes. Process Biochem. 40 1293-1299.

AZHAR SS, LIEW AG, SUHARDY D, HAFIZ KF and HATIM MDI (2005) Dye removal from aqueous solution by using adsorption on treated sugarcane bagasse. Am. J. Appl. Sci. 11 1499-1503.

BHATIA S, WONG CT and ABDULLAH AZ (2009) Optimization of air-borne butyl acetate adsorption on dual-function $\mathrm{Ag}-\mathrm{Y}$ adsorbent-catalyst using response surface methodology. J. Hazard. Mater. 164 1110-1117.

CAVACO SA, FERNANDES S, QUINA MM and FERREIRA LM (2007) Removal of chromium from electroplating industry effluents by ion exchange resins. J. Hazard. Mater. 144 634-638.

DAE WC and YOUNG HK (2005) Chromium (VI) removal in a semi continues process of hallow fiber membrane with organic extractants. Kor. J. Chem. Eng. 22 894-898.

DEAN JG, BOSQUI FL and LANOUETTE KH (1972) Removing heavy metals from wastewater. Environ. Sci. Technol. 6 518-524.

ELIBOL M (2002) Response surface methodological approach for inclusion of perfluorocarbon in actinorhodin fermentation medium. Process Biochem. 38 667-773.

FEBRIANTO J, KOSASIH AN, SUNARSO J, JU Y, INDRASWATI $\mathrm{N}$ and ISMADJI S (2009) Equilibrium and kinetic studies in adsorption of heavy metals using biosorbent: A summary of recent studies. J. Hazard. Mater. 162 616-645.

GHORBANI F, YOUNESI H, SEYED MG, ALI AZ, AMINI M and DANESHI A (2008) Application of response surface methodology for optimization of cadmium biosorption in an aqueous solution by Saccharomyces cerevisiae. Chem. Eng. J. 145 267-275. 
FRITZ W and SCHLÜNDER EU (1981) Competitive adsorption of two dissolved organics onto activated carbon. Chem. Eng. Sci. 36 721-730.

GARG U, KAUR MP, JAWA GK, SUD D and GARG VK (2008) J. Hazard. Mater. 154 1149-1157.

GUPTA VK and ALI I (2004) Removal of lead and chromium from wastewater using bagasse fly ash-a sugar industry waste. J. Colloid Interface Sci. 271 321-328.

KUMAR U (2006) Agricultural products and by-products as a low cost adsorbent for heavy metal removal from water and wastewater: A review. Sci. Res. Essay 1 033-037.

KUMAR U and BANDYOPADHYAY M (2006) Sorption of cadmium from aqueous solution using pretreated rice husk. Bioresour. Technol. 97 104-109.

KURT K, APAYDIN O and GONULLU MT (2007) Reduction of COD in wastewater from an organized tannery industrial region by Electro-Fenton process. J. Hazard. Mater. 143 33-40.

MARSHALL WE and JOHNS MM (1996) Agricultural by-products as metal adsorbents: sorption properties and resistance to mechanical abrasion. J. Chem. Technol. Biotechnol. 66 192-198.

MAHVI HA (2008) Application of agricultural fibers in pollution removal from aqueous solution. Int. J. Environ. Sci. Technol. 5 275-285.

MAVROV V, STAMENOV S, TODOROVA E, CHMIEL H and ERWE $\mathrm{T}$ (2006) Removal of nickel ions from wastewater by $\mathrm{Mg}(\mathrm{OH})_{2} /$ $\mathrm{MgO}$ nanostructures embedded in $\mathrm{Al}_{2} \mathrm{O}_{3}$ membranes. J. Alloys and Compounds 426 281-285.

McSWEENY JD, ROWELL RM and MIN SH (2006) Effect of Citric Acid Modification of Aspen Wood on Sorption of Copper Ion. J. Nat. Fibers 3 43-58.

PATEL H and MADAMWAR D (2002) Single and multichamber fixed film anaerobic reactors for biomethanation of acidic petrochemical wastewater-systems performance. Process Biochem. 36 613-619.

PAVIA DL, LAMPMAN GM and KAIZ GS (1987) Introduction to Spectroscopy: A Guide for Students of Organic Chemistry. WB Saunders, Philadelphia.

RAJI C and ANIRUDHAN TS (1997) Kinetics of Pb(II) adsorption by polyacrylamide grafted sawdust. Indian J. Chem. Technol. 4 157-162.
RAVIKUMAR K, KRISHNAN S, RAMALINGAM S and BALU K (2007) Optimization of process variables by the application of response surface methodology for dye removal using a novel adsorbent. Dyes Pigments 72 66-74.

SINGH R, MOODLEY K, ONYANGO MS, ODIYO JO and AOYI O (2007) Use of agricultural wastes to treat industrial wastewater: Review. Egerton University Research Week and International Conference, 15-20 July 2009, Njoro, Kenya. p. 483-490.

SHARMA P, SINGH L and DILBAGHI N (2009) Optimization of process variables for decolorization of Disperse Yellow 211 by Bacillus subtilis using Box-Behnken design. J. Hazard. Mater. 164 1024-1029.

SHUKLA A, ZHANG Y, DUBEY P, MARGRAVE JL and SHUKLA SS (2002) The role of sawdust in the removal of unwanted material from water. J. Hazard. Mater. $\mathbf{B 9 5}$ 137-152.

SITE AD (2001) Factors affecting sorption of organic compounds in natural sorbent/water systems and sorption coefficients for selected pollutants: A review. J. Phys. Chem. Ref. Data 30 187-439.

TATY-COSTODES VC, FAUDUET H, PORTE C and DELACROIX A (2003) Removal of $\mathrm{Cd}(\mathrm{II})$ and $\mathrm{Pb}$ (II) ions from aqueous solutions by adsorption onto sawdust of Pinus sylvestris. J. Hazard. Mater. 105 121-142.

WAFWOYO W, SEO CW and MARSHALL WE (1999) Utilization of peanut shells as adsorbents for selected metals. J. Chem. Technol. Biotechnol. 74 1117-1121.

WASE DAJ and FORSTER CF (1997) Biosorbents for Metal Ions. Taylor and Francis, London.

WORLD BANK GROUP (1998) Petrochemicals Manufacturing. Poll ution Prevention and Abatement Handbook 371-376. URL: http:// www.ifc.org/ifcext/enviro.nsf/AttachmentsByTitle/gui petrochem WB/\$FILE/petrochm_PPAH.pdf (Accessed 2 February 2009).

YANG T and LUA A (2003) Characteristics of activated carbons prepared from pistachio-nut shells by physical activation. J. Colloid Interface Sci. 267 408-417.

YU B, ZHANG Y, SHUKLA A, SHUKLA SS and DORRIS KL (2001) The removal of heavy metals from aqueous solutions by sawdust adsorption-removal of lead and comparison of its adsorption with copper. J. Hazard. Mater. 84 83-94.

ZHANG S, CHENG F, TAO Z, GAO F and CHEN J (2007) Removal of chromium from electroplating industry effluents by ion exchange resins. J. Hazard. Mater. 144 634-638. 